Article

\title{
Funds of Identity and Humanizing Research as a Means of Combating Deficit Perspectives of Homelessness in the Middle Grades
}

\author{
Matthew Moulton $(\mathbb{D}$ \\ Department of Teaching and Learning, Bayh College of Education, Indiana State University, Terre Haute, \\ IN 47809, USA; matthew.moulton@indstate.edu
}

Received: 26 July 2018; Accepted: 15 October 2018; Published: 17 October 2018

\begin{abstract}
Youth experiencing homelessness have seldom had the opportunity to contribute to conversations about policies and practices that impact their day-to-day lives. Brinegar highlighted middle level education research's contribution to the lack of representation of the voices of youth from marginalized perspectives. Where opportunities lack, dominant narratives persist. The word homeless often conjures deficit-laden images of ineptitude and unintelligence. This qualitative humanizing research study worked with one participant, $\mathrm{AJ}$, who created maps and other identity artifacts as a means of illuminating his funds of identity that were then analyzed using Creswell and Poth's data analysis spiral. Though results showed AJ to be a young adolescent with multiple funds of identity, the purpose of this article is to present how AJ draws great strength and purpose from his identity as a creator, despite transience between schools, who leverages technology for his personal and academic benefit. These results describe a young adolescent whose resilience and funds of identity transcend dominant narratives surrounding homelessness and point to opportunities for educator support in curriculum development and school-level policy.
\end{abstract}

Keywords: young adolescents; homelessness; funds of identity; humanizing research

\section{Introduction and Background}

Homelessness impacts rural, suburban, and urban schools all across the country [1]. Every day, as students filter through school doors, into classrooms, and populate desks, they bring with them every bit of their lived experience from outside the school walls. An educator's job is to ensure an equitable and appropriate educational experience for every student. Even with the widespread nature of homelessness, educators struggle with identifying students experiencing homelessness and how to best support them in their housing insecurity. The McKinney-Vento Homeless Education Assistance Improvements Act of 2001 [MV] was originally enacted in 1987 as the McKinney-Vento Act and was the first federal legislation implemented to address homelessness [2]. It mandated that students experiencing homelessness be provided access to the same equitable and appropriate educational experiences that all students have access to. It was not until 2001 that MV was amended and officially defined homeless as "individuals who lack a fixed, regular, and adequate nighttime residence" [2] (§ 725). According to MV, lacking a fixed, regular, and adequate nighttime residence includes children and youth who

- share the housing of other persons due to financial hardship, also known as "doubled-up";

- are living in motels, hotels, trailer parks, or camping grounds;

- are living in emergency or transitional shelters;

- are abandoned in hospitals; 
- $\quad$ are awaiting foster care placement;

- have a primary nighttime residence that is not designed as regular sleeping accommodation for human beings;

- live in cars, parks, public spaces, abandoned buildings, substandard housing, bus, or train stations, or similar settings;

- or are classified as migratory children who qualify as homeless.

During the 2014-2015 school year, the United States Department of Education documented 1.3 million cases that met the definition of student homelessness according to MV. Some experts believe that 1.3 million should be considered a conservative estimate and that the number is probably closer to 2.5 or 3 million $[1,3]$.

Regardless of where students experiencing homelessness are enrolled, their voices are seldom recognized as viable and vital with respect to their education and school experiences [4,5]. This echoes findings from Brinegar's content analysis of middle grades research literature in which the percentage of American children living in poverty is much larger than the percentage of middle grades research articles that address the education of students experiencing poverty $(22 \%$ living in poverty vs. $1 \%$ of reviewed middle grades publications) [6]. The Association for Middle Level Education [AMLE], the leading association for middle level education, identified four "Essential Attributes" and 16 "Characteristics" that successful schools for young adolescents must aim toward [7]. The four essential attributes and 16 characteristics can be found in Table 1.

Table 1. Essential attributes and characteristics of successful schools for young adolescents.

\begin{tabular}{ll}
\hline $\begin{array}{l}\text { Four Essential Attributes } \\
\text { An education for young adolescents must be }\end{array}$ \\
\hline Developmentally responsive: & $\begin{array}{l}\text { using the distinctive nature of young adolescents as the foundation upon } \\
\text { which all decisions about school organization, policies, curriculum, } \\
\text { instruction, and assessment are made. }\end{array}$ \\
\hline Challenging: & $\begin{array}{l}\text { ensuring that every student learns and every member of the learning } \\
\text { community is held to high expectations. }\end{array}$ \\
\hline Empowering: & $\begin{array}{l}\text { providing all students with the knowledge and skills they need to take } \\
\text { responsibility for their lives, to address life's challenges, to function } \\
\text { successfully at all levels of society, and to be creators of knowledge. }\end{array}$ \\
\hline Equitable: & $\begin{array}{l}\text { advocating for and ensuring every student's right to learn and providing } \\
\text { appropriately challenging and relevant learning opportunities for } \\
\text { every student. }\end{array}$ \\
\hline
\end{tabular}

\section{Characteristics}

Educators value young adolescents and are prepared to teach them.

Students and teachers are engaged in active, purposeful learning.

Curriculum is challenging, exploratory, integrative, and relevant.

Educators use multiple learning and teaching approaches.

Varied and ongoing assessments advance learning as well as measure it.

A shared vision developed by all stakeholders guides every decision.

Leaders are committed to and knowledgeable about this age group, educational research, and best practices.

Leaders demonstrate courage and collaboration.

Ongoing professional development reflects best educational practices.

Organizational structures foster purposeful learning and meaningful relationships.

The school environment is inviting, safe, inclusive, and supportive of all.

Every student's academic and personal development is guided by an adult advocate.

Comprehensive guidance and support services meet the needs of young adolescents.

Health and wellness are supported in curricula, schoolwide programs, and related policies.

The school actively involves families in the education of their children.

The school includes community and business partners. 
Brinegar's findings document the state of middle grades educational research and how aspects of that research ignore essential attributes and characteristics of an appropriate education for young adolescents [6]. Researchers who align themselves with young adolescents and AMLE's vision for schools should also align themselves with AMLE's vision or address it in their research [7]. It could be argued that the lack of representation in research and influential texts of young adolescents from marginalized populations represents a failure to provide an education that is simultaneously developmentally responsive, challenging, empowering, and equitable. Additionally, if educators truly value and are prepared to teach young adolescents who are experiencing homelessness, the research documenting their lived experiences needs to be present in influential literature.

This study begins to address the lack of representation of young adolescents experiencing homelessness in middle level education research. The purpose of this qualitative humanizing research study conducted with and for AJ (Pseudonym), a young adolescent experiencing homelessness from a small city in the southeastern United States, was to challenge dominant perceptions of who experiences homelessness and present a counter narrative that adds nuance to national data and statistics. Two research questions guided the inquiry.

1. What funds of identity do students experiencing homelessness possess?

2. How are these funds of identity supported, if at all, by school structures and personnel?

Merging humanizing research with funds of identity make it possible to present for readers one young adolescent's experiences in and out of school and how homelessness impacts all facets of life $[8,9]$.

This study used Esteban-Guitart's funds of identity as a tool that can be documented from the participant's perspective. Funds of identity, according to Esteban-Guitart, are "lived experiences ... that people use to express and understand themselves" [10] (p. 51). AJ documented multiple funds of identity but this article will expand upon one fund of identity, AJ as a creator. AJ's school both helps and hinders his identity as a creator. For example, he is helped by lax school-level technology policies that allow for engagement with his personal Wi-Fi-enabled phone while at school. He is hindered by a digital disconnect between where he and his classmates are with respect to using technology and where some of his teachers are. Educators could benefit from engaging with students, regardless of their housing situation, to learn about each child's funds of identity and personal interests and capabilities.

\section{Theoretical Framework}

This study employed humanizing research and the participant-engaged methods of funds of identity to challenge dominant narratives surrounding student homelessness [8,9]. Performing work with and for young adolescents from marginalized and high-risk backgrounds necessitates a level of sensitivity and attention to the relationships between participant and researcher. Humanizing research allows for personable interactions with an acknowledgment that the research interactions are not the totality of the participant or the researcher. Funds of identity, similarly, pulls researchers and participants closer together through the use of personal artifacts and the power structure of participants as experts.

\subsection{Humanizing Research}

Empowerment and change can revolve around relationships between researchers and participants. Paris defined humanizing research as "a methodological stance that requires that our inquiries involve dialogic consciousness-raising and the building of relationships of care and dignity for both researchers and participants" [8] (pp. 139-140). Winn and Ubiles described the necessity for researchers to be in a relationship with participants and to act as worthy witnesses [11]. This concept, picked up by Paris and Winn, requires researchers to invest fully in the participant relationship with dignity and aims to "decolonize and humanize the research process" [12] (p. xiii). Relationships are important in all research, but there needs to be an increased effort to develop positive relationships that foster 
kindness, patience, and care with individuals and communities who experience marginalization as a result of their race, ethnicity, class, gender, and other social and cultural categories [8].

Performing research with and for students experiencing homelessness must be a humanizing endeavor. Dominant narratives surrounding homelessness are very one-dimensional and involve dehumanizing deficit perspectives. Kim found that when asked to picture an individual experiencing homelessness, preservice teachers used adjectives including "dirty, hungry, drunken, addicted, or psychotic" [13] (p. 294). Additionally, as a result of the dominant societal narrative surrounding homelessness, young adolescents experiencing homelessness at times are "stereotyped as having a negative influence on other children in public school" [14] (p. 403). Students experiencing homelessness often experience shame and embarrassment at revealing the homelessness aspect of their living situation [15]. Humanizing research and the relationships it espouses focus on so much more than just a singular aspect of a person's identity [8].

For example, AJ and I interacted regularly during the course of 16 weeks of data collection. Part of the humanizing aspect of this study was our frequent meetings outside of traditional data collection methods. For example, we kept in touch via text. We had numerous conversations both before and after the audio recorder was turned on. We also shared meals together; not because I felt like AJ and his family were going to go hungry, but, because I like pizza. I knew AJ likes pizza; I knew his four younger brothers and sisters like pizza. I also knew that his grandmother would like not having to cook a meal once a week. When people are friends, and they value each other, they do things that out of a desire to care for each other.

\subsection{Funds of Identity}

Esteban-Guitart's funds of identity are a further elaboration of funds of knowledge [9]. A person's funds of knowledge "refer[s] to the historically accumulated and culturally developed bodies of knowledge and skills essential for household or individual functioning and well-being" [16] (p. 133). The act of uncovering funds of knowledge requires teachers to adopt a mindset of co-learner with students who are valued as the experts in their lives [17]. Funds of identity are cemented when individuals actively use their funds of knowledge to define themselves [9]. Funds of identity can be understood as the "lived experiences by the self that can include significant others, cultural tools, geographical places, institutions, and activities that people use to express and understand themselves" [10] (p. 51). According to Esteban-Guitart, these funds are historically accumulated, culturally developed, and socially distributed [9]. "Historically accumulated" refers to the notion that identities are constructed and influenced over time. A person's identity today is different from their identity tomorrow due to a further accumulation of influences. "Culturally developed" implies that identity is not genetically programmed into a person but develops in response to interactions "between the person and their sociocultural environment" [9] (p. 178). "Socially distributed" suggests that a person's identity "is transmitted and internalized through social interaction and participation in contexts of life and activity" (p. 178). Esteban-Guitart stated that funds of identity are essential for a person's self-definition, self-expression, and self-understanding.

There are five main funds of identity categories $[9,18,19]$. The first fund of identity category is geographical and involves identifying with any specific area or territory. The second category is practical and includes activities individuals participate in. The third fund of identity is cultural, which could include artifacts such as religious symbols or flags. The fourth, social funds of identity, includes significant others, relatives, friends, essentially identities that are pulled from taking part in relationships. The fifth, and last, fund of identity is institutional, which includes social institutions like marriage or family and also includes membership in institutions. The five types are summarized in Table 2. 
Table 2. Types of funds of identity.

\begin{tabular}{ccc}
\hline Type & Definition & Examples \\
\hline Geographical & $\begin{array}{c}\text { Any reference to an area such as a river, a } \\
\text { landscape, a mountain, a town, a city, a } \\
\text { country, or a nation. }\end{array}$ & $\begin{array}{c}\text { Canadian, Georgian, Athenian, } \\
\text { Appalachian }\end{array}$ \\
\hline Practical & $\begin{array}{c}\text { Significant activities for a person such as a } \\
\text { sport, music, or work. }\end{array}$ & Basketball, guitarist, drummer, barista \\
\hline Cultural & Artifacts such as flags or religious symbols. & Star of David, Sikh Khanda, cross \\
\hline Social & Relevant people. & Partner, family members, friends \\
\hline Institutional & $\begin{array}{c}\text { Any social institution such as references to } \\
\text { marriage or to a specific belief system. }\end{array}$ & Baptist, Sunni, university student, marriage \\
\hline & Note. Table 2 modified from Joves, Sisques, and Esteban-Guitart [1,9].
\end{tabular}

This article focuses solely on AJ's practical fund of identity as a creator. Practical funds of identity focus on actions or activities that individuals take part in. For example, practical funds of identity could include identifying as a writer, a researcher, and an amateur chef. Each of those practical funds of identity is accompanied by an action: writing, researching, and cooking. Additionally, practical funds of identity translate well into classroom settings and can be incorporated into curriculum $[10,18,20]$.

\section{Methods and Materials}

This qualitative research study conducted with and for AJ, a young adolescent experiencing homelessness, joined humanizing research with funds of identity and used participatory methods of data collection.

\subsection{Participant Recruitment}

AJ was recruited through a process that was approved by both his school district and my university. In consideration of extant research and the sensitivity of working with such a high-risk population, my IRB and school district approved recruitment protocol revolved around positive relationships that were already in place with key school or local service agency stakeholders. I developed recruitment materials, including a recruitment letter introducing myself and the goals for the study, a letter of consent for guardians, a letter of assent for the young adolescent participant, and instructions of how to opt in to the study. These packets were distributed by school personnel in discrete packaging to the potential participants. It was imperative that I remained at a distance during this first part of recruitment. From our interpretation of the National School Lunch Act, if I were to find myself in possession of identifying information before students opted in to the study both the school district and myself would have violated the students' rights to privacy and could possibly face a $\$ 1000$ fine or one year of jail time [21].

This process was arduous but wholly necessary. With the sensitivity and high-risk nature of working with individuals who were not only children but also technically homeless, I expected recruitment to be nothing less than complicated. After multiple road blocks recruiting through the school, I amended my recruitment protocols, sought another approval through my institution's review board, and approached five different social service agencies for assistance. Two of these agencies agreed to act as intermediaries and passed my recruitment materials on to individuals who might be interested. Recruitment, from start to finish, lasted five and a half months and resulted in one participant, AJ.

\subsection{Participant}

At the time of the study, AJ was an 11-year-old fifth grader who shared one room in a local family shelter with his four younger siblings and single mother. He carries himself with an air of maturity I have rarely encountered. Benson and Johnson described how youth experiencing homelessness 
almost need to mature faster than their stably housed peers [22]. At the time we met, $\mathrm{AJ}$ and I had both attended the same number of schools. I have attended seven, including my undergraduate and graduate school adventures. I was 33 years old and finishing a doctor of philosophy degree in education. AJ was 11 years old and only halfway through the fifth grade.

The number of schools he has attended is outnumbered by the number of places he has called home. AJ has lived in numerous different parts of this small southeastern city and fits nearly every definition of experiencing homelessness as defined by the McKinney-Vento Homeless Education Assistance Improvements Act of 2001 [2]. He has spent time in emergency shelters, family shelters, hotels, apartments, and houses. AJ, his mother, and four younger siblings were also doubled-up-meaning they shared housing with others because of loss of their own shelter due to financial hardship. In one instance, tripled-up might be more appropriate. Ten family members, spanning three generations, shared a three-bedroom apartment with just under 500 square feet of bedroom space. AJ's immediate family (six individuals) shared a small 132 square foot room and shared a bathroom with three other adult family members.

$\mathrm{AJ}$ and his mother gave their informed consent for inclusion before they participated in the study. The study was conducted in accordance with the Declaration of Helsinki, and the protocol was approved by the Human Subjects Research Office and Institutional Review Board of The University of Georgia.

\subsection{Data Sources}

There were three main data sources that were analyzed in this study: field notes, semi-structured interviews, and identity artifacts. My field notes were an attempt at capturing the details of my interactions with AJ [23]. While engaging in interviews/conversations and crafting identity artifacts with AJ, I recorded key details that I felt would be missed in only listening to an audio recording or reading a transcription of the interaction. For example, I took note of the group dynamic between AJ, his four younger siblings, and his three adult aunts. One night when I came to hang out with AJ, I found the eight of them huddled around a computer screen watching a movie together. Everyone was in each other's space but no one was uncomfortable with the close proximity. These field notes also served to capture instances when my personal beliefs and biases began to come in play and potentially influence how I was interpreting AJ's identity artifacts. As a continuation of the previous example, I attributed the close proximity during the movie night to be representative of how AJ and his family have had to share such small amounts of space by living in physically small spaces. I assumed that homelessness brought the family both physically and emotionally closer; however, I found out that this was a common practice predating the family's bout with homelessness.

I approached AJ's interviews with Stake's recommendations of providing guiding questions and tasks so that conversations result in a "description of an episode, a linkage, an explanation" [23] (p. 65). My semi-structured interviews followed Esteban-Guitart and Moll's identity artifact creation prompts [20]. I piloted the process of creating identity artifacts with teacher candidates in a class that I taught. The semi-structured interview protocol, which can be found in Appendix A, served as a foundation of sorts for conversations. I improvised the wording and order of questioning, using interview guide flexibly [24]. After the introductory interview, the identity artifacts AJ created served as elicitation devices. My interview protocols can also be found in Appendix A.

Esteban-Guitart stated:

[I]dentities or acts of identification can be materialized, encoded, or inscribed into tangible artifacts such as a diagram, a picture, a song, or any written, spoken, visual, or multimedia product. These are identity tools created by learners who invest in them and project onto them their meanings, interests, and so on. [10] (p. 44)

These artifacts can serve not only as vital sources of data that can be employed to work for the elimination of inequities but also as foundations for relationships of dignity and care between young 
adolescents and caring adults. Utilizing identity artifacts collaboratively with students experiencing homelessness allows the research team-adult and youth co-researchers-to "transport knowledge, experiences, situations, and practices in and out of school" [10] (p. 44). The identity artifacts utilized were participant-created maps and a significant circle.

Maps provide a direct line into the way that individuals see the world. Pacheco and Vélez shared that "Maps are visual artifacts of how people see the world as mediated by their particular value systems and relationships of power" [25] (p. 288). Maps can be extremely wide or they could be very local. Graue and Walsh wrote that working with and for children must be an intensely local process [26]. This intense locality requires navigating and dismantling the borders constructed between youth and adults. Utilizing maps and map-making serves as an attempt to gain intensely local insights about in and out of school experiences of youth who meet the United States federal government definition of homeless. When participants create artifacts, specifically maps, "different modes of expression" [27] (p. 327) present themselves that can often challenge societal narratives and other conventional, research-driven modes of inquiry.

Esteban-Guitart used the significant circle as an identity artifact in his work with students $[18,19]$. AJ was given a piece of paper with a circle drawn on it (Figure 4). He was then asked to write down the people, activities, and things that were most meaningful to him. The distance from the center of the circle represents a diminishing meaning to the creator [19]. Similar to map-making, significant circles become informative tools to uncover funds of identity when accompanied by interviews. This relational aspect of creation provides opportunities to strengthen humanizing connections between researcher and participant by opening up dialogic, mutual sharing.

\subsection{Data Analysis}

Data collection produced three maps, one significant circle, more than 100 pages of transcribed conversations, and field notes. I wanted to approach data analysis from a general process that still allowed for the "unusual and serendipitous" [28], (p. 185). I used Creswell and Poth's data analysis spiral, which allowed "moving in analytic circles rather than using a fixed linear approach" (p. 185). I was able to circle back to each part of data analysis with each additional step towards providing a thorough account of the study's findings. Creswell and Poth's data analysis spiral proceeds as: (a) data collection; (b) managing and organizing the data; (c) reading and memoing emergent ideas; (d) describing and classifying codes into themes; (e) developing and assessing interpretations; (f) representing and visualizing the data; and (g) an account of the findings.

I collected data during the research sessions where AJ crafted identity artifacts (see Figures 1-4) and discussed the components of the artifacts he created. Because I wanted to ensure access to my data regardless of the computer I was using while writing and analyzing, I created a password protected cloud folder to manage my data and writing. Then, I created a folder and named it AJ. The AJ folder had four different sub-folders in it: audio, identity artifacts, transcriptions, and field notes.

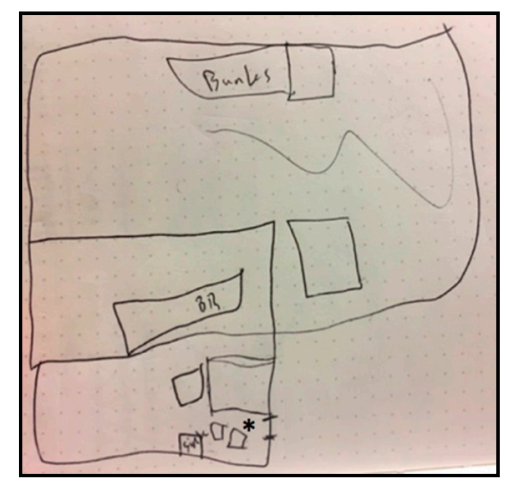

Figure 1. A floor plan, created by AJ, of the living space shared by the six family members. 


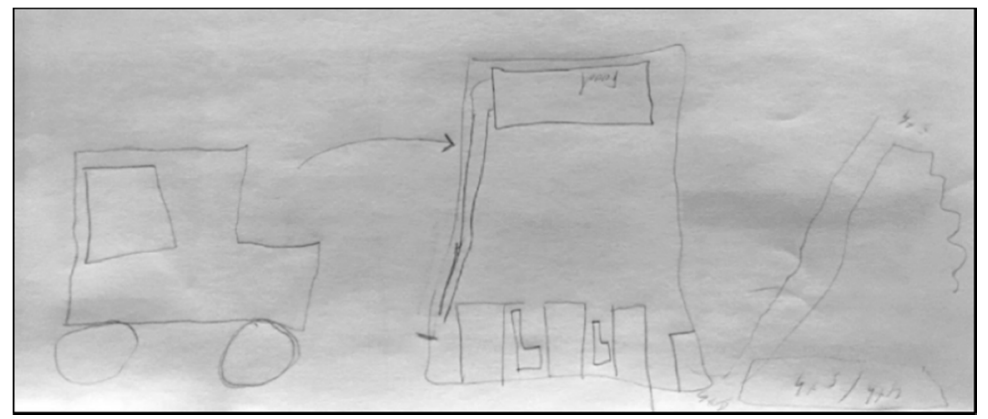

Figure 2. AJ's first map of school.

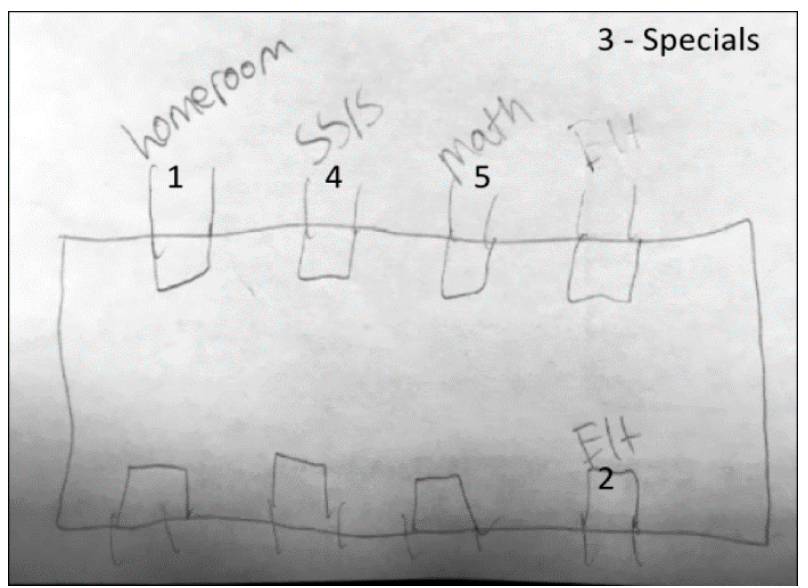

Figure 3. AJ's second map of his school. \#1 is his homeroom (Ms. Johns). \#2 is his ELT (extended learning time). \#3 represents his specials, which he attends on a rotating basis (music, P.E., art). \#4 is his social studies/science class. \#5 is his math class.

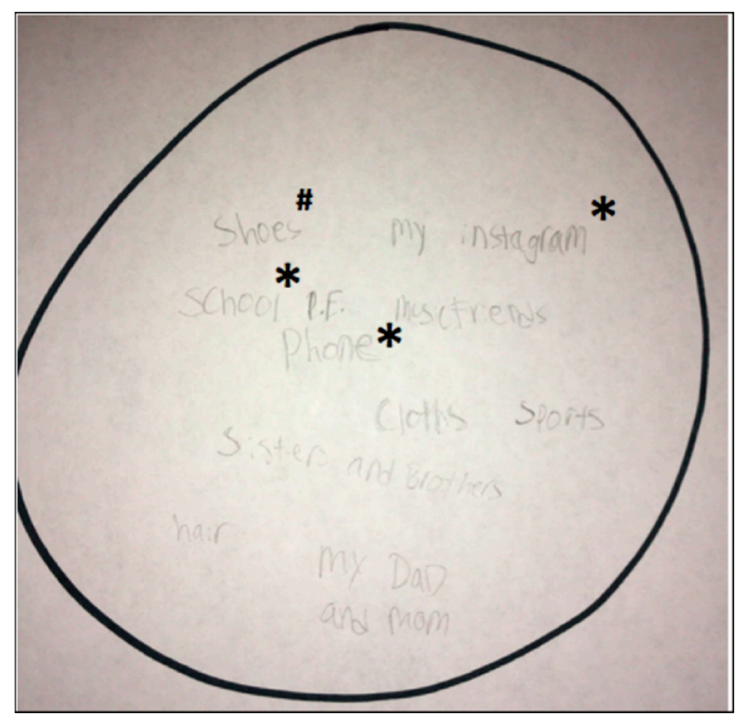

Figure 4. AJ's significant circle. Starting at the top and moving from left to right: Shoes, my Instagram, school, P.E., music, friends, phone (middle), clothes, sports, sisters and brothers, hair, my dad and mom.

Once all of the data were organized, I began reflecting on the data holistically. I started by rereading my field notes while listening to the audio recordings of the research sessions. While listening I took notes on how I was interpreting AJ's experiences and his potential emerging ideas or funds 
of identity, and I coded different portions of the data. Each of these emerging ideas was recorded in Table 3.

Table 3. Emerging ideas in data analysis.

\begin{tabular}{cccccc}
\hline Friends & Family & Shelter & Apartment & Sports & Food \\
Phone & Music & Instagram & Rap & Hair & PE \\
Shoes & Teachers & Schools & Bus & Clothes & Discipline \\
Dad & Cars & Drawing & Art & & \\
\hline
\end{tabular}

The emerging ideas were then elaborated upon, described, and classified into themes. For example, while listening to the research session where AJ crafted his significant circle, I took note of where he positioned his phone in the circle and how many times he referenced it throughout the activity. $\mathrm{AJ}$ 's phone was discussed in every single research session. My analysis included an elaboration of how he uses his phone and how integral it was to different portions of the data. This elaboration is pictured below in Figure 5.

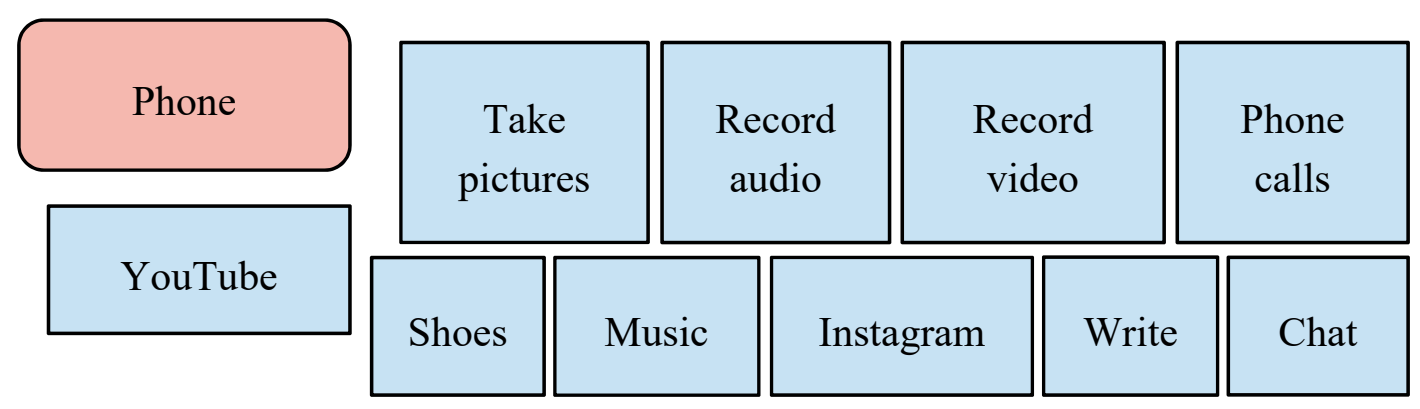

Figure 5. Emerging ideas from data analysis.

In Figure 5, AJ's phone is documented in the upper left-hand corner. All of the blue rectangles are ways that he uses his phone on a daily basis. He uses his phone to take pictures, record video, record audio, chat with friends, log in to social media, write, listen to music, watch videos, look at shoes, and make phone calls.

These emerging ideas were then described and classified into themes which, in turn, were developed into interpretations of AJ's experiences. I classified the emerging ideas into themes by either drawing categories and sorting or by digitally moving the blue rectangles into themes. A recreation of this can be found in Figure 6.

At this point, I approached AJ with my beginning understandings and interpretations of his funds of identity. This act, though commonplace in research, is considered to be a humanizing act. I worked with $\mathrm{AJ}$ and he crafted identity artifacts. I made assumptions about those artifacts. Reaching out for clarification and sharing what I had written is an intentional act of wanting to center $\mathrm{AJ}$ as the expert in his personal experience. I am just a conduit of his experiences to an academic audience. If I made assumptions and pushed my agenda without consulting the expert, I would do nothing to truly incorporate youth voices. This is one of the ways that this study is youth engaged. AJ is contributing to academic conversations about the experiences of youth identified as homeless. The beginning understandings I shared with AJ are recorded in Table 4.

I used member checking to verify my beginning understandings of AJ's funds of identity and how he is supported (or not) by school structures and personnel [29]. These member checks acted as intentional moves towards trustworthiness, credibility, and confirmability of the findings. The four funds of identity that I presented to AJ were friends, family, creator, and homeless. With his approval, I then proceeded to craft an account of the findings. 


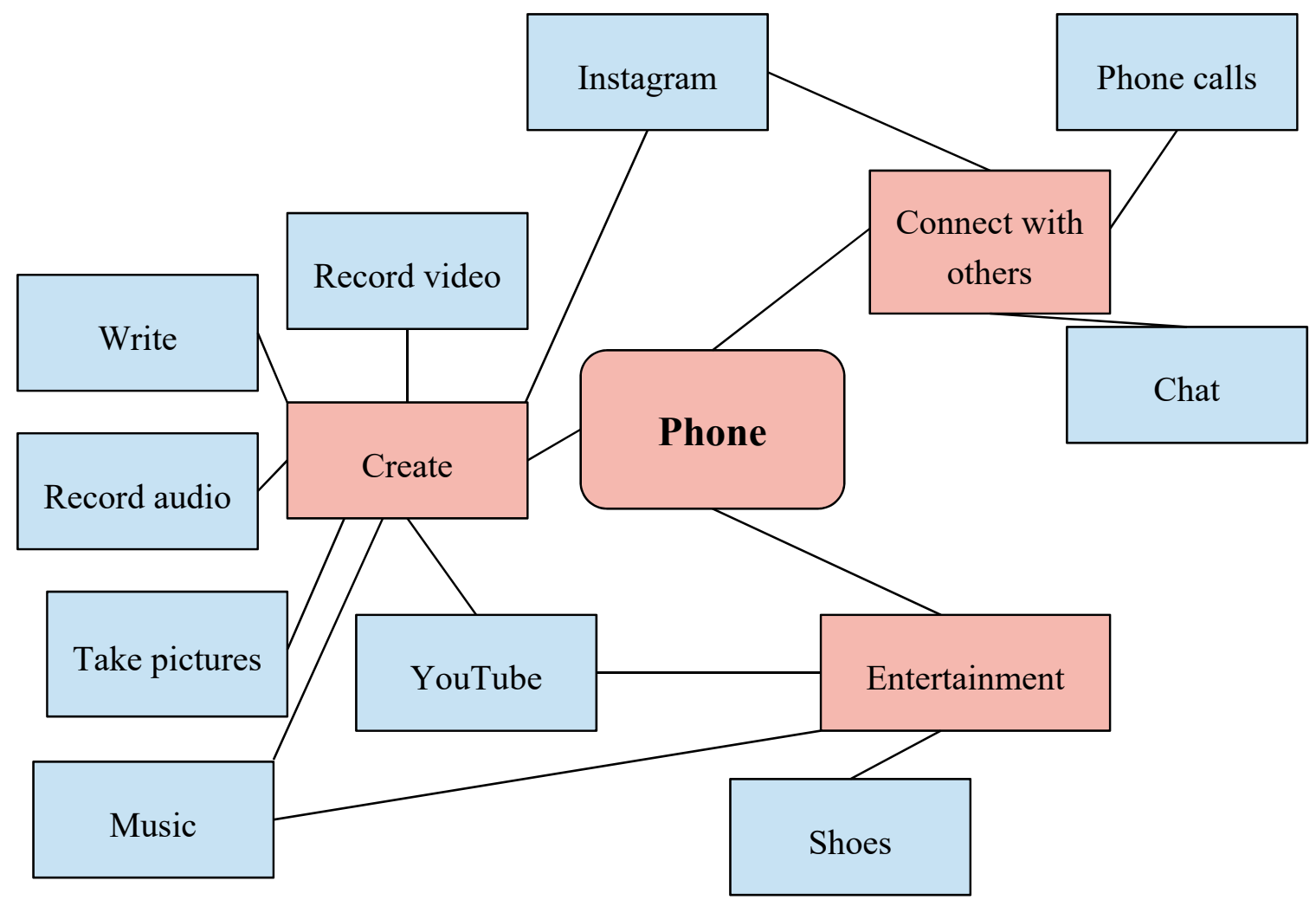

Figure 6. Phone themes.

Table 4. Beginning understandings of AJ's funds of identity.

\begin{tabular}{ll}
\hline Fund of Identity & Where in the Data This Fund Was Documented \\
\hline Family & $\begin{array}{l}\text { Field notes, introductory interview, map of shelter, discussion of school map, } \\
\text { significant circle, discussion of significant circle, member check }\end{array}$ \\
\hline Friends & $\begin{array}{l}\text { Field notes, introductory interview, map of school, discussion of school map, } \\
\text { significant circle, discussion of significant circle, member check }\end{array}$ \\
\hline Creator & $\begin{array}{l}\text { Field notes, introductory interview, discussion of school map, significant circle, } \\
\text { discussion of significant circle, member check }\end{array}$ \\
\hline Homeless & $\begin{array}{l}\text { Field notes, introductory interview, discussion of school map, discussion of } \\
\text { significant circle, member check }\end{array}$ \\
\hline
\end{tabular}

\section{Results and Discussion}

AJ's presented four main funds of identity for consideration during data collection and analysis. These identities included friend, family member, creator, and homeless. This article elaborates on AJ's identity as a creator and how his school could better support that identity.

\subsection{AJ's Identity Artifacts}

AJ created three maps during our research meetings and narrated the maps in accompanying conversations. The first map (Figure 1) was a floor plan of the family shelter that he, his mother, and four younger siblings resided in for four months. AJ's map did not include the only room in the shelter that had access to wireless Internet. He did, however, tell me about this room and its importance to him on a daily basis.

They don't have Wi-Fi here. No. There's nothing to do. There's only one room ... you know, that Internet provider store is right in front of the shelter. But there's one room in front ... inside the shelter. And that's all the rooms that got Wi-Fi. When nobody was in there, like, when nobody lived in 
that room, I would go in there all the time. And just stayed in there, too. Like, all night. But somebody got that room. Somebody moved in the room, so I can't go in there no more.

The Wi-Fi connection is the connecting thread that AJ shares with his friends outside of school. It is also the tool he uses to create music, videos, and pictures. His creator identity is mediated by access to Wi-Fi.

AJ also created a significant circle (Figure 4). The significant circle prompt and discussion protocol can be found in Appendix A. AJ's significant circle included 14 different items and included multiple references to his creative outlets of music, school, his phone, and Instagram. AJ and I had the following exchange while he crafted his significant circle.

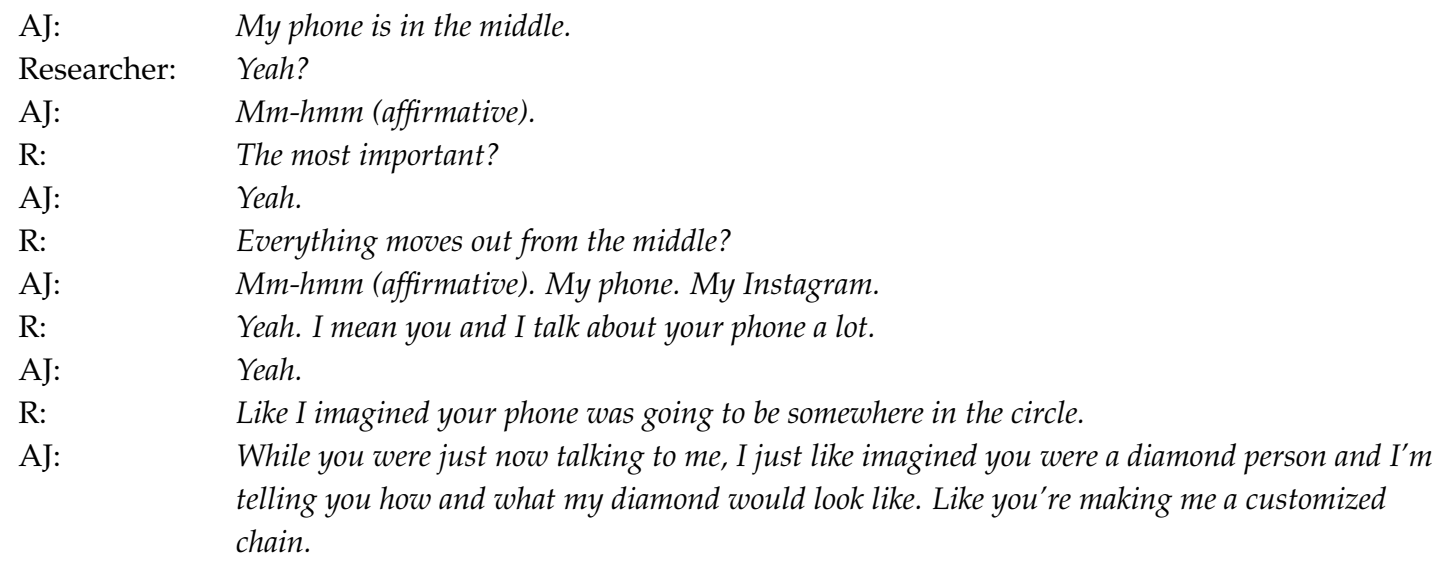

AJ took the prompts I gave him and created an imaginary scene that related the activity to his personal interests. He imagined that I was a custom jeweler who was tasked with creating a customized chain according to his desires. His willingness to vocalize his imagination is a testament to the humanizing relationship that we shared. We were not simply participant and researcher. We were pals who could laugh and make things while eating pizza and talking about life.

\subsection{AJ's Identity as a Creator}

Practical funds of identity include "any activity such as work, sports, and music" [9] (p. 177). Joves and colleagues describe practical funds of identity as significant activities that individuals participate in that impact their lived experience [19]. AJ has many significant activities that he takes part in, including but not limited to being a student, caring for his siblings, and exercising his agency and resourcefulness to meet his needs as a student experiencing homelessness. A practical fund of identity that I observed and spoke with $\mathrm{AJ}$ about is his identity as a creator.

AJ created identity artifacts as part of this research study but he also he creates identity artifacts and tools that promote further identity development in multiple spaces on a daily basis. The identity that AJ has cultivated in online spaces through Instagram posts and YouTube videos serves to both define and reify his relationships with friends and family members regardless of their physical proximity.

AJ talks about Instagram followers as a sort of status symbol and views them as a ticket towards notoriety.

AJ: $\quad$ Guess what? My friend Beth, she go to my school and she in the fifth grade but not in my class. She got 1000 followers.

R: $\quad$ Yeah? You'll get there. Something tells me you'll be there soon.

AJ: $\quad$ I know. If I got 1000 followers, I'm gonna end up getting the check mark. You know what that is?

R: $\quad$ Yeah, an official account?

AJ: Yeah, that means you famous. 
$\mathrm{AJ}$ is not only a creator of identity artifacts like significant circles, maps, videos, and pictures. $\mathrm{He}$ is also the creator of another life, a cultivated persona that is in no way homeless. His Instagram account is absent of the stigma associated with homelessness [30]. He chooses to create these artifacts and post them in ways that do not depict his housing insecurity. AJ records his YouTube videos at his grandmother's apartment. The furnishings of an apartment distract viewers away from dominant narratives surrounding homelessness. Creating videos, taking pictures, furnishings, and brightly colored clothes run counter to the dominant narratives and depictions of homelessness in popular culture (e.g., [13,31]).

Young adolescents' identities are known to evolve and vary across digital and physical contexts and purposes [32]. The identity that AJ presents to classmates and followers through social media accounts takes work and is a real time commitment. His YouTube channel has short videos of him dancing or rapping. The videos may be short, but the work AJ puts into creating them is substantial. He told me that if he posts a rap video he needs to:

1. write it using the notes app on his phone,

2. rehearse the rap,

3. find a good backdrop,

4. enlist a family member to hold the phone while recording, and

5. find a place that has the Wi-Fi bandwidth to upload a video to YouTube.

AJ's Instagram posts are similarly cultivated and come with another set of considerations. AJ experienced a bit of a crisis when this creator fund of identity was put at risk, saying:

I got scared one time. I thought my Instagram got deleted. I thought my aunty did it, because when I was visiting her I was making my little cousin, Cory, an account. And so he said, "Can you put your Gmail for me?" And so I put my Gmail in and so he had an account, but he was signed into my Gmail on it, though. So, my aunty called me and said, "AJ, what's Cory's password on his tablet?" And I was like, "I forgot it." And so she changed it herself, but when she changed his, she ended up changing mine too. I didn't know the password and I asked her, "You messed up my Instagram. What's the password?" She didn't say nothing. She didn't even respond back. So I had to sign in, get help signing in, and I just signed in on my own. My name, my username. I typed that in and then I could log in. I got scared though.

AJ wanted to be able to connect with Cory and create using Instagram to the point that he allowed Cory to use his personal Gmail account and almost lost his account in the process. As an adult, I get frustrated when I forget passwords. I am so used to having immediate access that the inconvenience of needing to wait for something is upsetting. There are a few differences between my experiences with forgetting passwords and AJ's:

1. Unlike AJ, I have a personal Internet connection and do not need to find strategic places around the city to gain access,

2. Unlike AJ, I have a personal phone line that I can use as long as I am in a location that has cell service, and

3. Unlike AJ, my connection to stability and familiarity is not dependent upon gaining access to a social media account.

The conversations about school that occurred while making maps showed the relationship between school and AJ's identity as a creator of art, especially music. He enjoys music class. The opportunities available in his music class are influenced by student choice and include learning to play the guitar. The influence of music ripples out from school and is also found in his YouTube videos where he dances and sings. Music, art, and physical education are on a rotating schedule at AJ's school and he only has music class every third day. He enjoys the topics of all three classes, but finds the content of his art class boring and unengaging. He said: 
Everybody hates art. Nobody likes art. It's so boring. It's just like, we always have to color and junk. They make us color with crayons and markers. Like, boring baby stuff. Like, not even kindergartners like art. Nobody likes art. Everybody walks into art and they'd [shrug and tune out]. Art teacher be sitting there still talking like she don't care. She would just keep teaching. She think we like art, but we don't.

There exists a digital disconnect between how $\mathrm{AJ}$ engages with art using his Wi-Fi-enabled phone and what his teachers allow in their classes. The artistic elements of his Instagram pictures and YouTube videos show a young adolescent who is willing to take risks and try different things.

The digital disconnect begs the question, Why adults (teachers, administrators, stakeholders, etc.) do not allow young adolescents to use the Internet freely in school spaces? So much of AJ's identity is influenced by his access to an Internet connection and social media tools. His phone is a connection to and creation tool of another life. Do the risks of opening up the Internet for youth outweigh the rewards? AJ should be allowed to use the Internet. It is something that he uses to keep in touch with friends. It brings him joy.

\subsection{Supports for AJ's Creator Fund of Identity}

AJ says that the friendships formed at each of the six previous schools he has attended have survived the frequent moves and lack of physical proximity. He believes that this is mostly thanks to the creative outlets of social media apps on his phone. He uses Instagram, YouTube, messenger apps, and phone calling apps to keep in touch with his family and friends from the different schools he has attended. I asked him how many of his friends from the different schools he has attended have phones. He responded, "All of them. If I didn't have my phone, I would be mad because I wouldn't be able to text someone or nothing."

AJ passes his time and connects with his friends digitally using an Android powered smartphone and a Wi-Fi connection. He wields his phone skillfully and uses it to create. He takes pictures for Instagram, records videos for YouTube and Instagram Video, listens to music on Spotify, writes rap lyrics in note-taking apps, and records himself using music publishing apps. The phone was documented as one of the most important things in AJ's life and he placed it almost in the direct center of his significant circle (Figure 4). His phone is a great source of pride. I asked him if he is able to use the phone at school and he responded by saying:

Me and all my friends like to play on our phones at recess. It's kind of like, the teachers will say if you have your phone out or anything, like it's on you. Because if you get it stolen then ... [shrugs]

... But at the same time, they don't really want us on our phones. We can't do nothing on them, though because there are no hotspots, so we just take pictures and listen to music.

AJ's phone plays a major part in his life. The school's rather lax technology policy allows AJ and his classmates to use their personal devices at various times during the day and use it as a sort of social currency with his friends. That being said, the school's lack of accessible Wi-Fi for students limits AJ's engagement on school grounds.

AJ's homeroom teacher, Ms. Johns, also supports his identity as a creator by allowing him to exist in confidence that she will not reveal that he experiences homelessness to his friends and classmates. AJ describes Ms. Johns as nosey. He said, "She is so nosey! She watches our computer screens all day. The other teachers will look every once and a while but my homeroom teacher always watches, 24/7." He does not hold the invasion of privacy against her and understands that she is trying to make sure that students are on task. He noted, "Some kids playing games on their computer when they're not supposed to." I laughed at this, half suspecting that he has been counted in the ranks of "some kids" due to another exchange we had where he told me: "I like to get in some trouble sometimes."

I wanted to ask him if he feels supported by Ms. Johns but before I could get the full question out he said, "Do I think she would tell my friends? No." This is important. When AJ is at school he does not have to display the homeless fund of identity that is outwardly ascribed onto him by district 
personnel, his teachers, myself, and society's dominant narratives. He can be AJ the creator. His teacher knows about the vulnerable state he is in and seeks opportunities to give him the same in school experience as his stably housed classmates and friends. The environment that Ms. Johns has helped to cultivate, knowingly or not, is one of support, advocacy, and care which challenges dominant narratives surrounding homelessness and allows $\mathrm{AJ}$ to be a creator of physical, digital, and emotional products. She may not outwardly confront the societal perceptions of homelessness but she has provided a space where $\mathrm{AJ}$ is able to emote and display his other funds of identity, adding to the nuance and complexity that is his young adolescent identity.

The school district's transportation policies also impact AJ's creator fund of identity. $\mathrm{AJ}$ is the first student picked up by the school bus in the morning and the last one dropped off so that knowledge that he currently resides in the shelter is not revealed to other students. The result is an adolescent in waiting and separation from creative outlets that require $\mathrm{Wi}-\mathrm{Fi}$ connections. The time that $\mathrm{AJ}$ is on the school bus in the mornings is equal to more than 33 total school days (Conservative estimate based on numbers relayed by AJ. Roughly 90 min of travel time each day multiplied by 180 days, equals 16,200 min of travel time per school year. 16,200 min divided by $60 \mathrm{~min}$ in an hour, equals $270 \mathrm{~h}$ of travel time per school year. Estimating that a school day measures roughly $8 \mathrm{~h}, 270 \mathrm{~h}$ divided by $8 \mathrm{~h}$ in a day, equals 33.75 school days.). AJ spoke at length about how he utilizes Wi-Fi technologies to create and how he is bored on his long bus rides before and after school.

I was bored. Like there was nothing to do, so I just (starts to smile)... Our bus monitor, he's real old and he talk like... Our bus monitor is old. He like 50-something. And I was just bored or something like ... I didn't have no Wi-Fi. Couldn't play on my phone and then so I did ask, "Why do you always wear church shoes in school?"

On the school bus before and after school, AJ does not have the ability to, quite literally, get connected. It is possible for his school district to pick up students experiencing homelessness in district vehicles other than school buses and deliver them discreetly to school without classmates discovering the rationale for transport. This would not only allow for students like AJ to sleep later in the morning, but it would allow him to reclaim time that could be applied to his funds of identity such as friends, family, and being a creator. In all honesty, AJ could walk home faster than the bus can drive him home.

\subsection{Interconnectedness of $A J$ 's Funds of Identity}

Esteban-Guitart described how an individual's funds of identity could simultaneously fall within the bounds of more than one type of fund of identity [9]. Esteban-Guitart and Moll described the funds of identity uncovered through identity artifact creation as "internalized meanings from social context" [18] (p. 44). Putting a wall around these internalized meanings and classifying them as solely social or solely practical ignores the interconnectedness of an individual's funds of identity. AJ's creator fund of identity serves as a tool to connect with friends and family. AJ creates identity artifacts in the form of Instagram pictures and YouTube videos so that he can participate in the social aspects of social media with friends and family. Esteban-Guitart stressed that funds of identity are historically and socially constructed [9]. AJ's current funds of identity could look different if we were to create a significant circle again or craft a new map of his school. This reality does not make the findings any less valuable or less informative. Teaching is contextual and teachers must always work to adapt and modify their craft. Teachers must be in constant contact with their students so that students' funds of identity can be identified and incorporated in course curriculum. The funds of identity of young adolescents experiencing homelessness are influenced by the variability of adolescence itself and are compounded by the transience of homelessness. Teachers who interact with students experiencing homelessness on a daily basis must be able to recognize and work with these intersectionalities. 


\section{Conclusions}

This research study revealed AJ's creator fund of identity. This identity should not be viewed as his sole identity or as if it is an identity that all individuals experiencing homelessness possess. Like Kozol stated, "The use of the unrestrictive term, 'the homeless,' is in certain ways misleading. It suggests a uniform set of problems and a single category of poor people ... the uniformity is in their mode of suffering, not in themselves" [33] (p. 115). Part of the purpose of this study was to put a human face on homelessness and to re-humanize narratives surrounding homelessness. That being said, the work of documenting these counter narratives should not rest on the individuals experiencing homelessness themselves. Advocates must come alongside.

$\mathrm{AJ}$ is a young adolescent who engages in the creation of identity artifacts like pictures, music, and videos, which he shares via social media using his Wi-Fi-enabled cellphone that does not have a data plan. Despite not being able to make use of all his phone's capabilities at all times, he leverages the phone for personal benefit and maintains friendships across distances and against the odds. Within his school, AJ has a few adult advocates as he discussed during our research meetings. Should he, and other students experiencing homelessness, wish to succeed, they will need the advocacy, support, and empathy of adult advocates along the way.

Adult advocates are of paramount importance for young adolescents. AMLE's 16 "Characteristics of Successful Schools for Young Adolescents" from This We Believe reference the importance of caring adults in multiple places [7]. The document stated that middle grades classrooms must be staffed with individuals "who choose to work with and advocate for young adolescents" (p. 15). Education stakeholders must collaborate with young adolescents to inform a relevant curriculum. Educators must be in constant dialogue with students, aware of their interests and hopes so that "teaching approaches capitalize on skills, abilities, and prior knowledge" (p. 22). Middle level educators should keep abreast of the latest research, policy, and popular culture that impact young adolescents. This We Believe also called on adult advocates to consider their own interpersonal relationships with each other because "the school itself is a teacher and ... students learn not only from the instruction offered but from implicit lessons as well" [7] (p. 30). Probably the most explicit mention comes with the essential characteristic, which stated "Every student's academic and personal development is guided by an adult advocate" (p. 35).

The McKinney-Vento Homeless Education Assistance Improvements Act of 2001, in much less flowery language, called for similar supports for students experiencing homelessness [2]. Neither of these guiding texts should be viewed as superior over the other but they must be employed in concert by school faculty and staff to address the needs of young adolescents experiencing homelessness.

In conclusion, I would like to pose three questions for readers to ask of themselves and of their research. Considering AJ's experiences, interests, and funds of identity, how can the schools we work with and for better meet the needs of every student? What are the ways that we can better engage with young adolescents' funds of identity in and out of class settings? If we asked the young adolescents in our charge if they felt supported by the adult advocates in their school buildings, would we be open to any and all responses? The answers could be very telling as to what we believe about students, their identities, and how we can best support them.

Funding: This research received no external funding.

Acknowledgments: This work was emotionally and grammatically supported by Gayle Andrews. I would also like to thank Micki Caskey for editing this special issue.

Conflicts of Interest: The author declares no conflict of interest

\section{Appendix A. Data Collection Protocols}

\section{Semi-Structured Interview Protocol}

During Initial Meeting 
1. Tell me about your experiences in school.

a. What are some things that you like about the school?

b. What are some things that you would change if you had the opportunity?

\section{Identity Artifact Protocol}

Identity Artifact Creation

\section{Map-Making}

1. Draw a map of your school

a. Label the map with the places that you go (classes, lunch, before/after school, places you hang out, etc.)

2. Identify people/places/things on the map that are strengths of your school

3. Identify people/places/things on the map that you feel could be improved

4. Conversation taking place after creation of map:

a. Describe what you included in your map

b. What were the strengths you listed?

i. What about them makes you consider them strengths?

c. What were the things that could be improved?

i. What about them makes you think they could be improved?

\section{Significant Circle}

Participants will be given a piece of paper with a large circle on it.

1. I would like for you to write down the people, activities, and things that are most meaningful to you in the big circle. Write inside some smaller circles the most significant people and write inside a small square activities, hobbies, or things. I would like for you to think about the center of the circle as being the most important to you. The further something is from the center of the circle the less important it is to you.

2. Conversation to take place after the significant circle is created:

a. Describe what you included in your significant circle.

Why did you include these things?

\section{References}

1. National Center for Homeless Education. Education of Homeless Children and Youth (EHCY) Federal Data Summary for School Years 2012-2013 to 2014-2015; National Center for Homeless Education: Greensboro, NC, USA, 2016.

2. United States Federal Government. The McKinney-Vento Homeless Education Assistance Improvements Act of 2001; United States Federal Government: Washington, DC, USA, 2015.

3. United States Department of Education. Supporting the Success of Homeless Children and Youth [Fact Sheet]; United States Department of Education: Washington, DC, USA, 2016.

4. Aviles De Bradley, A.M. Unaccompanied homeless youth: Intersections of homelessness, school experiences, and educational policy. Child Youth Serv. 2011, 32, 155-172. [CrossRef]

5. Saldanha, K. Promoting and developing direct scribing to capture the narratives of homeless youth in special education. Qual. Soc. Work. 2015, 14, 794-819. [CrossRef] 
6. Brinegar, K. A content analysis of four peer-reviewed middle grades publications: Are we really paying attention to every young adolescent? Middle Grades Rev. 2015, 1, 4.

7. National Middle School Association. This We Believe: Keys to Educating Young Adolescents; National Middle School Association: Westerville, OH, USA, 2010.

8. Paris, D. 'A friend who understands fully': Notes on humanizing research in a multiethnic youth community. Int. J. Qual. Stud. Educ. 2011, 24, 137-149. [CrossRef]

9. Esteban-Guitart, M. Towards a multi methodological approach to identification of funds of identity, small stories and master narratives. Narrat. Inq. 2012, 22, 173-180. [CrossRef]

10. Esteban-Guitart, M. Funds of Identity: Connecting Meaningful Learning Experiences in and out of School; Cambridge University Press: New York, NY, USA, 2016; ISBN 1107147115.

11. Winn, M.T.; Ubiles, J.R. Worthy Witnessing: Collaborative Research in Urban Classrooms. In Studying Diversity in Teacher Education; Ball, A., Tyson, C., Eds.; American Educational Research Association: Washington, DC, USA, 2011; pp. 295-308, ISBN 1442204419.

12. Paris, D.; Winn, M.T. Humanizing Research: Decolonizing Qualitative Inquiry with Youth and Communities; SAGE: Thousand Oaks, CA, USA, 2014; ISBN 1452225397.

13. Kim, J. Against the unchallenged discourse of homelessness: Examining the views of early childhood preservice teachers. J. Early Child. Teach. Educ. 2013, 34, 291-307. [CrossRef]

14. Crook, C. Educating America's homeless youth through reinforcement of the McKinney Vento Homeless Assistance Act. Faulkner Law Rev. 2015, 6, 395-408.

15. Ellis, A.L.; Geller, K.D. Unheard and unseen: How housing insecure African American adolescents experience the education system. Educ. Urban Soc. 2016, 48, 583-610. [CrossRef]

16. Moll, L.C.; Amanti, C.; Neff, D.; Gonzalez, N. Funds of knowledge for teaching: Using a qualitative approach to connect homes and classrooms. Theory Into Pr. 1992, 31, 132-141. [CrossRef]

17. Moll, L.C.; Gonzalez, N. Lessons from the research with language minority children. J. Read. Behav. 1994, 26, 439-455. [CrossRef]

18. Esteban-Guitart, M.; Moll, L.C. Funds of identity: A new concept based on the funds of knowledge approach. Cult. Psychol. 2014, 20, 31-48. [CrossRef]

19. Joves, P.; Siques, C.; Esteban-Guitart, M. The incorporation of funds of knowledge and funds of identity of students and their families into educational practice. A case study from Catalonia, Spain. Teach. Teach. Educ. 2015, 49, 68-77. [CrossRef]

20. Esteban-Guitart, M.; Moll, L.C. Lived experience, funds of identity and education. Cult. Psychol. 2014, 20, 70-81. [CrossRef]

21. United States Federal Government. The Richard B. Russell National School Lunch Act; United States Federal Government: Washington, DC, USA, 2014.

22. Benson, J.E.; Johnson, M.K. Adolescent family context and adult identity formation. J. Fam. Issues 2009, 30, 1265-1286. [CrossRef] [PubMed]

23. Stake, R.E. The Art of Case Study Research; SAGE: Thousand Oaks, CA, USA, 1995; ISBN $080395767 X$.

24. Patton, M.Q. Qualitative Research and Evaluation Methods; SAGE: Thousand Oaks, CA, USA, 2002; ISBN 0761919716.

25. Pacheco, D.; Vélez, V.N. Maps, mapmaking, and critical pedagogy: Exploring GIS and maps as a teaching tool for social change. Seattle J. Soc. Justice 2009, 8, 273-302.

26. Graue, M.E.; Walsh, D.J. Studying Children in Context: Theories, Methods, and Ethics; SAGE: Thousand Oaks, CA, USA, 1998; ISBN 0803972571.

27. Clark, A. Breaking methodological boundaries? Exploring visual, participatory methods with adults and young children. Eur. Early Child. Educ. Res. J. 2011, 19, 321-330. [CrossRef]

28. Creswell, J.W.; Poth, C.N. Qualitative Inquiry E Research Design: Choosing among Five Approaches, 4th ed.; SAGE: Thousand Oaks, CA, USA, 2018; ISBN 1506330207.

29. Schwandt, T.A. The SAGE Dictionary of Qualitative Inquiry, 3rd ed.; SAGE: Thousand Oaks, CA, USA, 2007; ISBN 1412909279.

30. Toolis, E.E.; Hammack, P.L. The lived experience of homeless youth: A narrative approach. Qual. Psychol. 2015, 2, 50-68. [CrossRef]

31. Pimpare, S. Ghettos, Tramps, and Welfare Queens: Down and out on the Silver Screen; Oxford University Press: New York, NY, USA, 2017; ISBN 0190660724. 
32. Steinkuhler, C. Cognition and Literacy in Massively Multiplayer Online Games. In Handbook of Research on New Literacies; Coiro, J., Knobel, M., Lankshear, C., Leu, D., Eds.; Lawrence Erlbaum: New York, NY, USA, 2008; pp. 611-613, ISBN 0805856528.

33. Kozol, J. Rachel and Her Children: Homeless Families in America; Crown: New York, NY, USA, 1988; ISBN 0307345890.

(c)

(c) 2018 by the author. Licensee MDPI, Basel, Switzerland. This article is an open access article distributed under the terms and conditions of the Creative Commons Attribution (CC BY) license (http://creativecommons.org/licenses/by/4.0/). 